\title{
Dynamic market impacts of generic dairy advertising ${ }^{2 \pi}$
}

\author{
Charles F. Nicholson *, Harry M. Kaiser \\ Cornell University, Ithaca, NY 14853-7801 USA
}

\begin{abstract}
Generic advertising of fluid milk and cheese represents the principal promotional activity undertaken with the $\$ 370$ million per year provided by dairy farmers and fluid milk processors. This article describes a stock-flow-feedback simulation model that includes 17 intermediate and final dairy products, short-term and long-term milk supply response and government policies that influence the impacts of generic advertising on net revenues for dairy farmers. Permanent increases in generic advertising expenditures increase net revenues for dairy farmers, with a cumulative net benefit to cost ratio of 2.8. Permanent decreases produce a larger reduction in net revenues and indicate a net benefit to cost ratio larger than 4.5 . Spending a larger proportion of existing generic advertising funds on cheese rather than fluid milk would also markedly increased dairy farmer net revenues. Generic advertising increases net revenues for dairy farmers even when industry supply response and government regulation are accounted for.
\end{abstract}

Keywords: Generic advertising; Dairy; System Dynamics; Simulation models

Dairy farmers pay a mandatory assessment of 15 cents per hundred pounds of milk marketed in the continental United States to fund a national demand expansion program. This assessment generally ranges between 0.75 and $1 \%$ of the price farmers receive for their milk, and most of the money supports generic advertising of fluid milk (e.g., Got Milk?) and cheese (e.g., Behold the Power of Cheese) products. The aims of generic milk and dairy product advertising are to increase consumer demand for fluid milk and dairy products, enhance dairy farm revenues, and reduce the amount of surplus milk purchased by the government under the Dairy Price Support Program. Legislative authority for these assessments dates back to the Dairy Production and Stabilization Act of 1983. More recently, fluid milk processors began their own generic fluid milk advertising program (e.g., the Milk Mustache print media campaign) funded by a mandatory $\$ 0.20$ per hundred

\footnotetext{
is The authors acknowledge the helpful comments and suggestions of Peter Otto, George Richardson and other participants in the workshop System Dynamics and Marketing Strategy held at Cornell University, May 31 and June 1, 2007.

* Corresponding author. Cornell Program on Dairy Markets and Policy, Department of Applied Economics and Management, Cornell University, Ithaca, NY 14853-7801 USA.

E-mail addresses: cfn1@cornell.edu (C.F. Nicholson),hmk2@cornell.edu (H.M. Kaiser).
}

pounds processor check-off on fluid milk sales. These two programs represent the two largest generic advertising programs in the United States, raising $\$ 370$ million per year.

Generic advertising differs from traditional branded advertising in several important ways. First, although branded advertising is an individual firm's activity, generic advertising is a collective effort by all firms within an industry. Second, branded advertising attempts to differentiate a firm's product from its competitors; generic advertising is not geared at product differentiation and is most successful for products with homogeneous characteristics such as basic commodities. Third, the goal of generic advertising is to increase overall demand for a commodity, whereas branded advertising is primarily firm market share driven. A final distinction is that dairy generic advertising's ultimate goal is to increase both the quantity and price of a raw input (milk) through shifts in the demand curve for dairy products requiring that input.

The long-run effectiveness of the program in increasing demand and the price of milk will depend critically on the nature of the milk supply response. For example, if the long-run supply curve for the industry is perfectly elastic, any increase in demand due to generic advertising will not increase price or producer surplus. In contrast, demand increases with an upward sloping long-run supply curve increase both price and producer surplus 
under effective generic advertising. Consequently, modelers must explicitly link supply response to demand and price increases due to advertising to evaluate the impact of generic dairy advertising.

Because dairy is the largest generic advertising program, numerous studies on the economic impacts of generic dairy advertising exist (see Ferrero et al. (1996) for an annotated bibliography). This research falls into two broad categories. The first category of research is positive in nature, evaluating the economic impacts of generic advertising on dairy markets. The majority of this research indicates that generic advertising increases overall market sales and prices at farm, wholesale and retail market levels, and that the benefits of generic advertising substantially outweigh the costs. Kaiser (2006) found a benefit-cost ratio of 4.32 for fluid milk and cheese advertising by dairy farmers. The second line of research is normative in nature, investigating optimal allocation issues. Studies include optimal spatial allocation of advertising by markets (Liu and Forker, 1990), allocation of advertising over time (Vande Kamp and Kaiser, 2000), allocation of advertising across products (Kaiser and Forker, 1993), allocation of advertising by media type (Pritchett et al., 1998) and allocation of expenditures by marketing and research activity (Chung and Kaiser, 1999). All these studies use econometric methods, optimization, or a combination of both. No previous studies of the impacts of generic dairy advertising employ stock-flowfeedback models that include explicit balancing of dairy component (e.g., fat, protein, lactose) to assess market impacts.

Two characteristics of US dairy markets create challenges for researchers interested in modeling the impacts of generic dairy advertising. First, the US dairy industry is highly regulated. Milk pricing at the farm, dairy processor and retail levels depends on federal and state milk marketing orders (which regulate minimum prices that must be paid to farmers), the Dairy Price Support Program (which provides a farm-level price floor and safety net through government purchases of selected dairy products), and import tariffs (which complement other price-related policies by dramatically limiting imports of some dairy products). Properly incorporating the impacts of these regulations on prices is essential for sound evaluation of generic advertising. Second, raw milk is a commodity that has many components with different end uses. Modeling all the possible uses for these components and the associated component-based pricing structure of the regulated market is a complicated process. Nearly all previous studies of generic advertising's impacts deal with these issues through simplifying assumptions about milk components and a high degree of aggregation for dairy products. They therefore omit potentially important linkages that could affect the accuracy of predicted model outcomes (Bishop et al., 1994). These two characteristics of the dairy market make the use of a model with disaggregated representation of dairy products, components and price regulations policy instruments quite appealing.

Accordingly, this paper has four objectives. The first is to examine the dynamic market impacts of increases and decreases in generic advertising expenditures for both fluid milk and cheese in a multiple-product dynamic simulation model. The analysis also allows the computation of a cumulative benefit-cost ratio to assess the effectiveness of generic advertising in a dynamic context. The second objective is to determine the allocation of fluid milk and cheese expenditures that maximizes net revenues received by dairy farmers for a given level of generic advertising expenditures. A third objective is to demonstrate the applicability of a systems modeling approach to the evaluation of generic advertising. A final, broader, objective is to contribute to understanding of how generic advertising influences product markets.

\section{Model description}

A causal diagram illustrates a number of the differences between the impacts of generic and branded advertising (Fig. 1). The diagram depicts a number of balancing (B) and reinforcing (R) feedback processes associated with the impacts of generic advertising. In contrast to branded advertising, the ultimate objective of generic advertising is to increase net revenues for input suppliers (dairy farmers in this case). The mechanism for this is as follows. Generic advertising expenditures increase sales of the advertised products, which decreases inventories (a physical stock, depicted with a box in Fig. 1), increases their price, increases the net margin earned from them and stimulates additional production. Increases in production of the advertised product increase the demand for the raw input (milk) needed as an input. Increased raw input use for the manufacture of advertised products (in this case, fluid milk and cheese) decreases the availability of the raw input to manufacture non-advertised products (e.g., butter, dried milk). This reduces the available supply of nonadvertised products, increasing their price. As noted above, minimum raw input price regulation exists in the US dairy industry; the minimum price paid to farmers is calculated as a function of product prices and product for which the raw input is used. An increase in the price of non-advertised products increases the minimum regulated price. The price increase for advertised products also contributes to increases in the minimum regulated price. A higher minimum regulated price increases the net revenues earned by raw input suppliers (the objective), but also increases input costs for all products. The input cost increase increases the prices of all products, which will have a dampening effect on demand.

Fig. 1 facilitates discussion of the principal balancing and reinforcing processes at work in the US dairy industry. The term balancing loop (B) implies that an initial change in one of the variables in the loop will ultimately result in pressure for that variable to move in the direction opposite the change, all other things being equal. In contrast, a reinforcing loop (R) indicates than an initial change will be reinforced through the feedback process. More formally, feedback loop polarity is $\operatorname{SGN}\left(\varphi X_{1}^{\text {Output } / ~}\right.$ $\left.\varphi X_{1}^{\text {Input }}\right)$ where SGN is the sign function, $X^{\text {Output }}$ is the value of a variable $X$ after one feedback cycle in response to an initial change in the value of $X^{\text {Input }}$ (Sterman, 2000).

Conceptually, three feedback processes have an important impact on the ultimate effectiveness of generic advertising to achieve its objective of increasing input supplier net revenues (Fig. 1). The production response loop is a typical market response: increased profitability of advertised production results in additional supplies, increasing inventories and reducing price relative to what would have occurred in the absence of a production response. The second feedback process (the regulated 


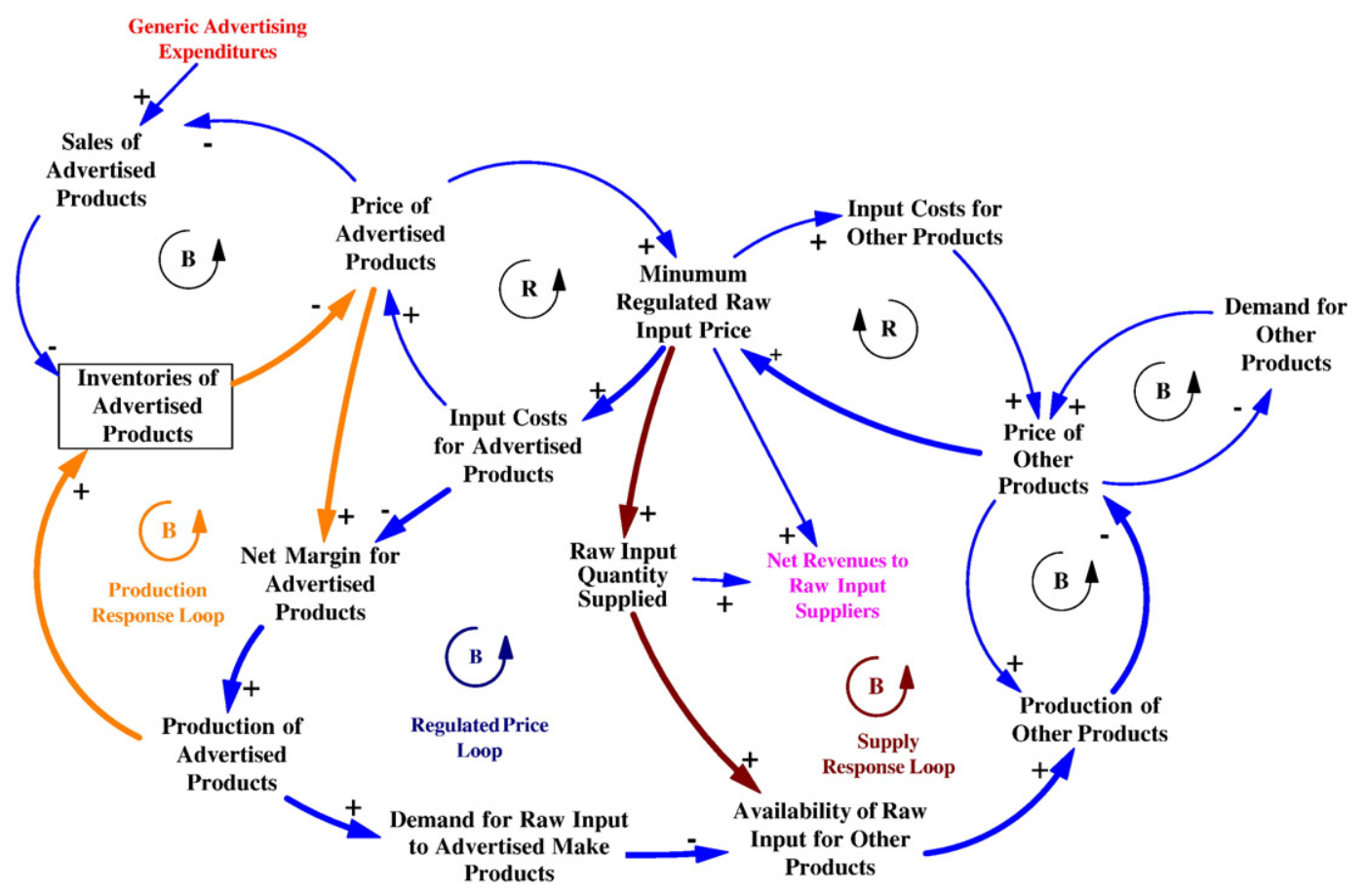

Fig. 1. Causal diagram of generic advertising effects in the US dairy sector.

price loop) implies that the effects of generic advertising will be offset to a certain extent through increases in input costs for all dairy product manufacturers through increases in the minimum regulated price. Supply response by input suppliers (the supply response loop) indicates that increases in the price for the raw input supplier will increase the quantity supplied of the raw product. This increases the availability of the raw input for use in the manufacture of non-advertised products, decreasing those product prices compared to what they would have been. An important issue in the evaluation of generic advertising expenditures is the extent to which the production response, the minimum price regulation and raw input supply response feedback processes erode the effectiveness of advertising expenditures over time.

To evaluate the effectiveness of generic advertising in the dairy industry context, a more detailed empirical model is necessary. This model builds upon a previous conceptual commodity (Sterman, 2000) and the dairy industry price determination model in Nicholson and Fiddaman (2003). To capture the effects of minimum price regulation, the model includes a total of 17 final and intermediate dairy products. In most dairy-related models, intermediate products are those dairy products used in the manufacture of other dairy products. A common example is the use of dried milk in cheese manufacturing. Final products are those used by non-dairy manufacturers (e.g., other food processors) or final consumers. Perishable products such as fluid milk, yogurt and ice cream are flow variables for which production is equal to sales. Commercial inventories of storable commodities such as butter, cheese, dried milk and dried whey (used in the minimum pricing formulae) are stock variables, where production increases inventories and sales reduce them. Increases in commercial inventories of these products result in decreases in the prices of these products. In the dairy industry, manufacturers separate raw milk into a variety of components (butterfat, proteins, lactose and minerals) using various physical processes (e.g., filtration). As a result, dairy models should adequately represent the physical balance of these components across different product uses. The model includes the use of skim milk and cream components to capture component balance. Essentially, cream represents fat and skim milk represents protein, lactose and minerals.

In addition to the minimum regulated pricing that operates in the dairy industry, other key policy interventions include price supports for selected manufactured products (butter, cheese and dried milk) and restrictions on dairy product trade. Price supports operate through the willingness of the Commodity Credit Corporation (CCC; established by the federal government) to purchase dairy products at prices designed to maintain a minimum level of milk prices paid to dairy farmers, or through direct payments made to farmers when milk prices fall below a target level. Dairy trade policies restrict the quantities of many imported (storable) products, which historically has maintained US milk and dairy product prices above those in international markets. Although under recent market conditions these policies have limited impact on the effectiveness of generic advertising and are not shown in Fig. 1, the empirical model includes them.

Supply response occurs through changes in both productivity per unit of capital (milk production per cow per year) and changes in the capital stock (the number of cows). Productivity responds with a delay to changes in the price of the raw input (milk) in the short run (complete response to a step change in the milk price relative to a reference price occurs within about 3 months), whereas the number of cows responds to an exponential smooth (another delay) of relative net margins over 3 years. The number of cows results from a biological reproduction rate (assumed to be 
constant) and the rate of removal of animals from the aggregated national herd, which depends on the profitability of milk production. The rate of removal is the inverse of the average animal lifetime, which is a function of current margins relative to long-term expectations. The degree to which dairy farmers modify average animal lifetimes in response to relative margins is unknown, so the impacts of this parameter on simulated outcomes are evaluated with sensitivity analysis.

The impact of generic advertising on the demand for fluid milk and cheese is modeled as a modified multiplicativereference formulation (Sterman, 2000) as follows:

$\left.\operatorname{Sales}_{\mathrm{jt}}=\operatorname{SMOOTH}\left[\text { ales }_{\mathrm{jt}}^{\mathrm{REF}} \cdot \frac{P_{\mathrm{jt}}}{P_{j}^{\mathrm{REF}}}\right)^{\eta_{j}} \cdot \operatorname{MAX}\left\{\left(\mathrm{MP}_{j}, \frac{\mathrm{GAE}_{\mathrm{jt}}}{\mathrm{GAE}_{j}^{\mathrm{REF}}}\right)^{\gamma_{j}}\right\}, \mathrm{AT}\right]$

Sales $_{\mathrm{jt}}^{\mathrm{REF}}=\operatorname{Sales}_{j}^{2004} \cdot\left(1+\theta_{j}\right)^{t}$

This formulation implies that sales of advertised dairy product $j$ at time $t$ are a function of a sales in the 2004 reference (base) year, product price $P_{j}$ relative to reference price, and the maximum of the effect of generic advertising expenditures relative to their 2004 reference value or a minimum assumed proportion, $M P_{j}$, of the reference dairy product sales in the absence of generic advertising expenditures (GAE). The minimum proportion term is necessary to avoid zero sales in the absence of generic advertising. The parameters $\eta_{j}$ and $\gamma_{j}$ are elasticities of sales with respect to price and generic advertising expenditures, respectively. Reference sales values grow over time at proportional monthly growth rates $\theta_{j}$ due to exogenous population and income growth. To reflect delays in the adjustment of consumer behavior to changes in price and generic advertising expenditures, the specification assumes exponential smoothing with a time constant of one month.

The model is formulated as a system of nonlinear differential equations solved by numerical integration. Parameter values for behavioral responses to prices and inventory levels and the initial stock values are from previous dairy industry models (Bishop and Nicholson, 2004; Nicholson and Fiddaman, 2003), data from the Agricultural Marketing Service of the US Department of Agriculture (which administers the minimum pricing regulations), and an extensive network of industry contacts (Cornell Program on Dairy Markets and Policy, 2006). Values of the elasticity of fluid milk and cheese demand with respect to advertising expenditures are from Kaiser and Dong (2006), and are equal to 0.037 and 0.035 , respectively. Values of the elasticity of fluid milk and cheese demand with respect to price come from Schmit and Kaiser (2004) and Bishop and Nicholson (2004) and are equal to -0.2 and -0.5 , respectively. The model simulates all variables at monthly time intervals over the six-year period 2004 to 2009 using a small calculation interval to approximate a continuous-time system. Model evaluation followed the process Sterman (2000) describes. A previous version of the model evaluated the impact of growth in dairy product demand on dairy farmer revenues (Nicholson and Stephenson, 2006). For the purposes of the analyses herein, underlying growth in demand for dairy products (i.e., outward shifts in the demand curves) in response to increases in household income and population are exogenous, and are from Nicholson and Stephenson (2006) and Schmit and Kaiser (2006). Although the financial resources for generic advertising in the dairy industry derive from assessments on dairy farmers and fluid milk processors (and thus depend on milk production and sales of fluid milk) the allocation of funds to generic advertising is not proportional to funds available, so generic advertising expenditures are exogenous.

\section{Model scenarios}

Two rather stylized types of analyses of the dynamic market impacts of generic advertising are the focus herein (Table 1). The first is an analysis of permanent (i.e., step) changes in generic advertising in the presence of growth in demand for dairy products, and the second is an analysis of which proportional allocation of 2004 advertising expenditures between fluid milk and cheese maximizes cumulative discounted dairy farmer net revenues. For each of these scenarios, the impact of two assumed values of the long-term supply response (sensitivity of average animal lifetime to profitability) is evaluated. For the baseline scenarios, the value of the sensitivity of average animal lifetime in response to relative net margins is equal to 1.0 ; for scenarios termed less sensitive, the value of this parameter is 0.5 . The average animal lifetime uses a multiplicative-reference (constant elasticity) formulation in which the average lifetime is equal to a reference lifetime modified by the ratio of current smoothed net margins divided by a reference net margin to the power of the sensitivity parameter described above.

The model is initialized using the average values of product prices, production and dairy product inventories for 2004. Baseline scenarios include 2004 levels of generic advertising expenditures and constant proportional growth in dairy product demand (the $\theta_{j}$ discussed above). Step changes in generic advertising occur in January 2006 and continue until December 2009. Differences between the baseline scenario and scenarios with step changes indicate the impact of increasing or decreasing generic advertising expenditures.

Table 1

Generic advertising scenarios analyzed

\begin{tabular}{ll}
\hline Scenario $^{1}$ & Implementation \\
\hline Baseline & $\begin{array}{l}\text { Assumed exogenous growth rates for dairy products } \\
\text { and 2004 level of generic advertising expenditure; } \\
\text { allocations between fluid milk and cheese as in 2004 }\end{array}$ \\
$\begin{array}{l}\text { Increase generic } \\
\text { advertising }\end{array}$ & $\begin{array}{l}\text { and cheese by 100\% from 2004 levels as a } \\
\text { permanent (step) change beginning in January 2006 }\end{array}$ \\
Eliminate & $\begin{array}{l}\text { Eliminate generic advertising on both fluid milk and } \\
\text { cheese as a permanent (step) change beginning in }\end{array}$ \\
$\begin{array}{l}\text { Generic } \\
\text { Advertising }\end{array}$ & $\begin{array}{l}\text { January 2006 } \\
\text { Optimal product } \\
\text { allocation of generic }\end{array}$ \\
advertising & $\begin{array}{l}\text { advertising expenditures between fluid milk and } \\
\text { cheese as a permanent step change beginning in }\end{array}$ \\
& January 2006 \\
\hline
\end{tabular}

${ }^{1}$ For each of the scenarios, the impact of two assumed values of the long-term supply response (sensitivity of average animal lifetime equal to 0.5 or 1.0 ) is evaluated. 


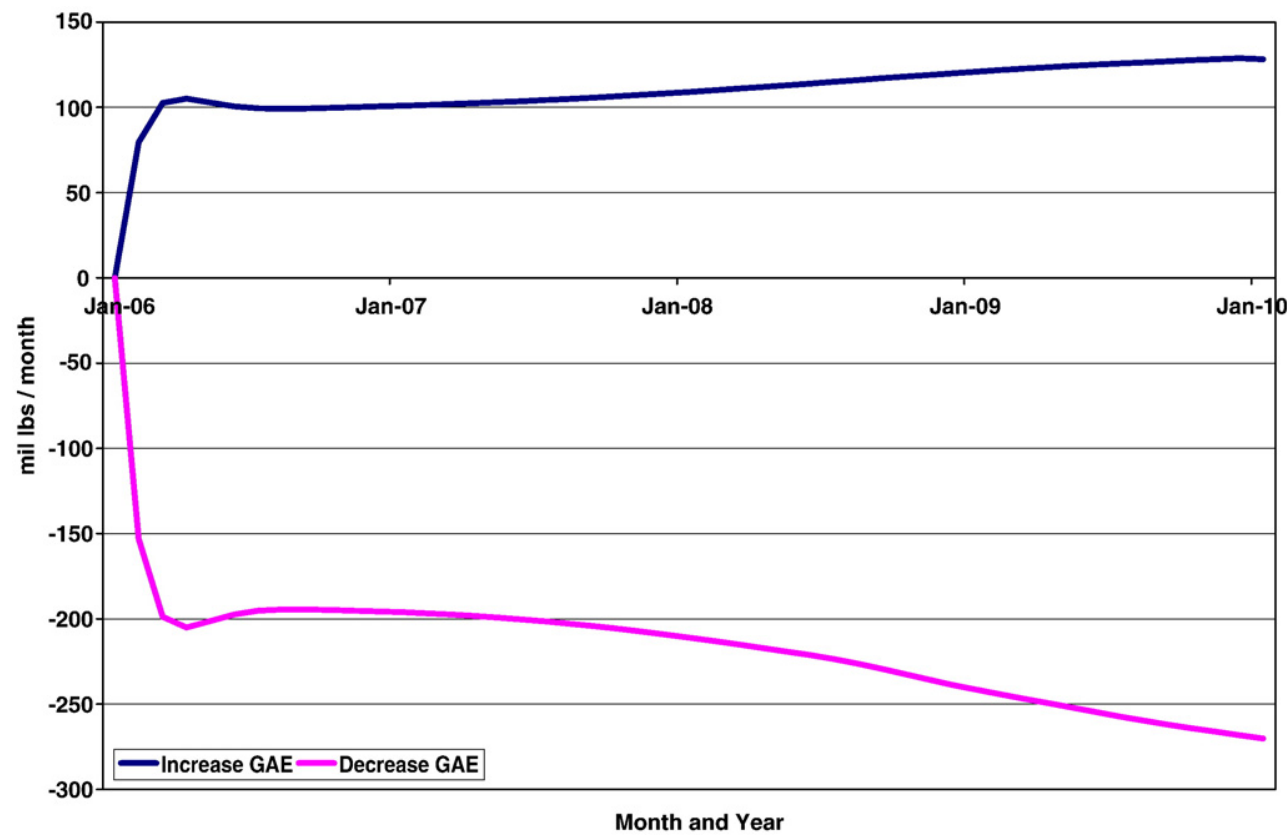

Fig. 2. Fluid milk sales in response to increases and decreases in generic advertising expenditures, difference from baseline.

Key outcome variables of interest are changes in product sales, changes in selected dairy product prices, changes in dairy farmer net revenues (monthly and cumulative revenues from milk sales less production costs), milk production (supply response) and the cumulative net benefit-cost ratio (CNBCR; the ratio of changes in dairy farmer net revenues to changes in overall generic advertising expenditures). The changes in cumulative dairy farmer net revenues and the CNBCR are calculated from January 2006, when changes in generic advertising expenditures occur. The results of each of the scenarios relative to the baseline indicate the impact of the change in generic advertising amounts or allocations. Because of the nonlinear feedback dynamics present in the system, each of these variables is likely to vary over time. The dynamic benefitcost ratio of generic advertising, previously evaluated only in a static sense for dairy generic advertising, is of particular interest.

\section{Results}

\subsection{Impacts of step increases or decreases in generic advertising expenditures}

A permanent increase in generic fluid milk and cheese advertising expenditures initially increases fluid milk and cheese sales during the first few months relative to the Baseline (Fig. 2

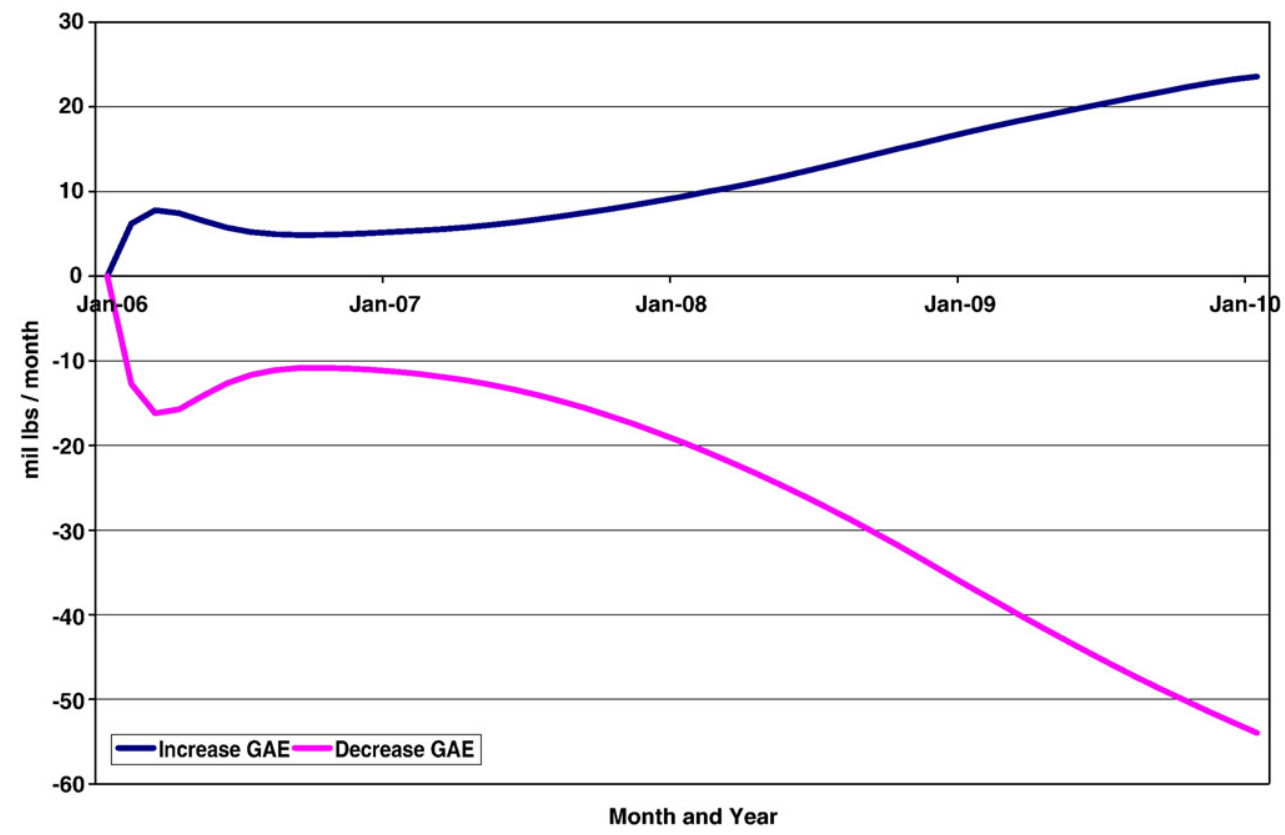

Fig. 3. Cheese sales in response to increases and decreases in generic advertising expenditures, difference from baseline. 


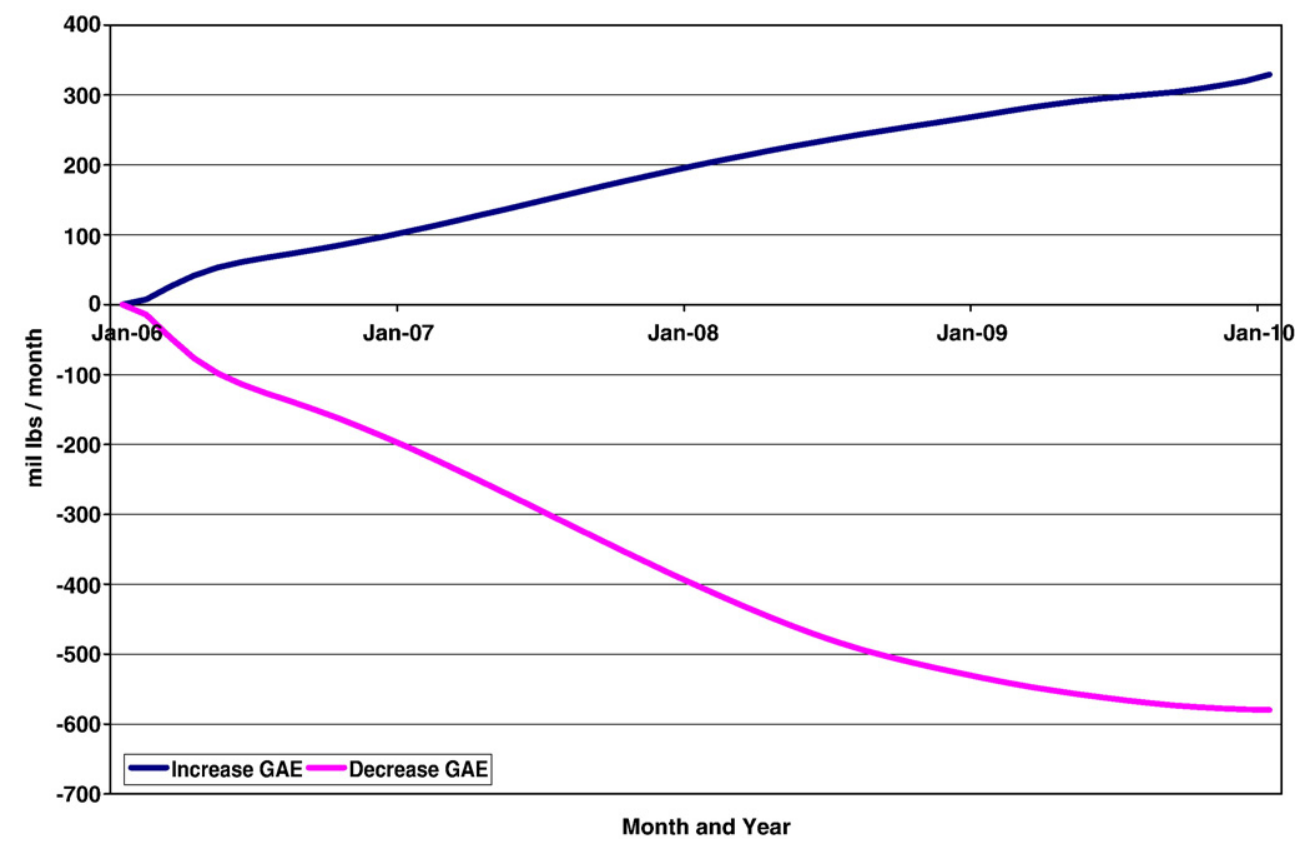

Fig. 4. Milk production in response to increases and decreases in generic advertising expenditures, difference from baseline.

and 3). The demand for raw milk to manufacture these products rises more quickly than milk production (Fig. 4) due to milk supply response delays arising from cow reproductive biology and farm-level decision making. The availability of milk for non-advertised products decreases and their price increases (Fig. 5 indicates this for butter), which results in an increase in the minimum regulated price (Fig. 6). The price of cheese increases (Fig. 7), which also contributes to an increase in the minimum regulated price, and cumulative producer net revenues increase relative to the baseline (Fig. 8). Thus, the initial effects of the increase in generic advertising expenditures have the desired outcome of increasing producer net revenues.

Over time, however, the effectiveness of the increase in expenditures is eroded by the balancing feedback processes. As consumers respond to price increases brought about by increased demand for the raw milk to make fluid milk and cheese, a relatively small decrease in fluid milk sales from their peak value occurs during the next 12 months (Fig. 2). A similar

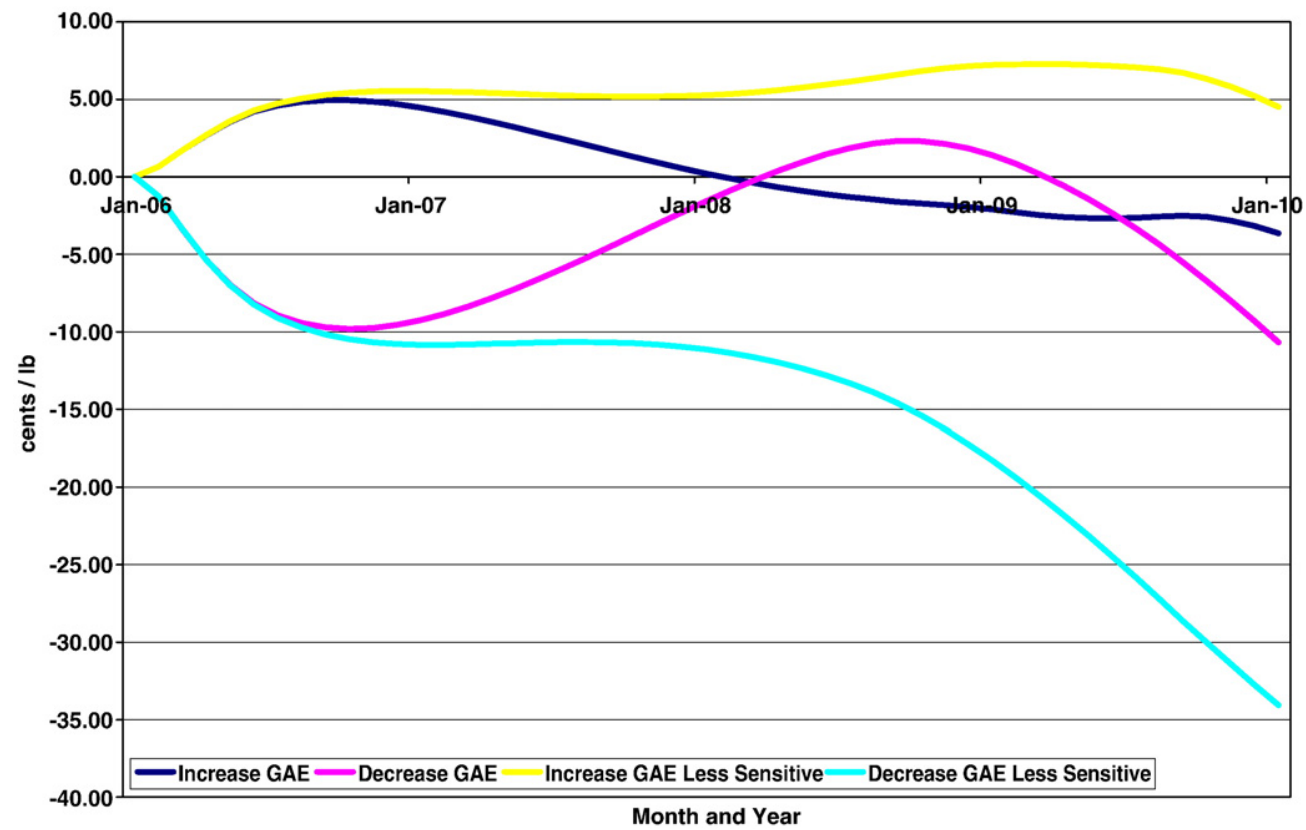

Fig. 5. Butter prices in response to increases and decreases in generic advertising expenditures, by sensitivity of capital investment response, difference from baseline. 


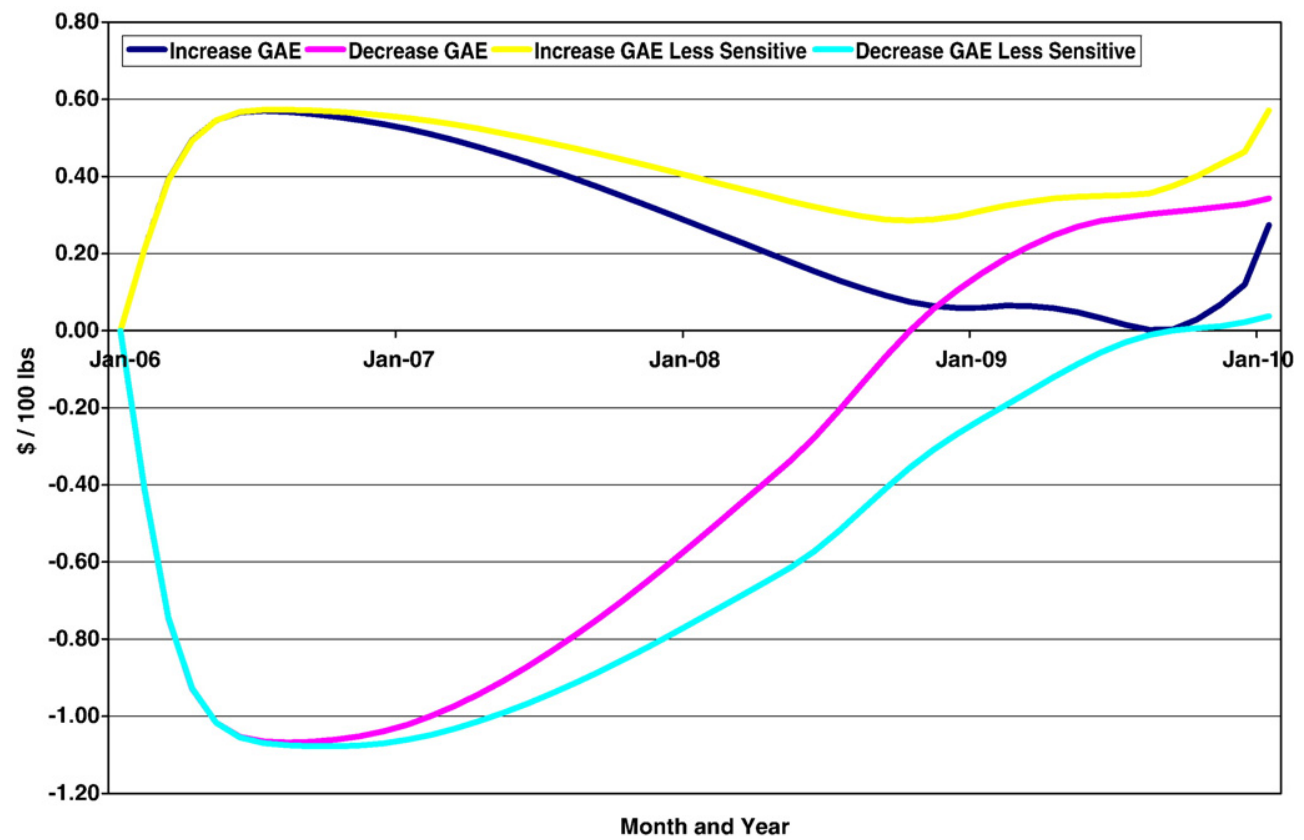

Fig. 6. Producer milk price from in response to increases and decreases in generic advertising expenditures, by sensitivity of capital investment response, difference from baseline.

pattern of behavior is observed for cheese sales (Fig. 3), but demand growth resumes in 2007 and continues through 2010 because the underlying growth rate for cheese sales is $1.5 \%$ per year. Dairy producers respond with a delay to the increased minimum regulated prices, increasing both productivity and the capital stock (cows), which increases milk supplies. As more milk is produced (Fig. 4) and demand for fluid milk and cheese is dampened through the consumer response, more milk is available for use in non-advertised products. Increased production of those products decreases their price (Fig. 5), increased cheese production (the production response loop from Fig. 1) decreases the cheese price (Fig. 7), and the minimum regulated price decreases. The increase in the minimum regulated price due to an increase in generic advertising expenditures falls from a peak of nearly $\$ 0.60$ per $100 \mathrm{lbs}$ in mid-2006 to less than $\$ 0.10$ per $100 \mathrm{lbs}$ by late 2008 (Fig. 6) as a result of supply response. After January 2008 the rate of increase of the difference in cumulative producer net revenues slows markedly (Fig. 8).

Permanent elimination of generic advertising expenditures initially reduces fluid milk and cheese sales by a larger amount than the permanent increase raises them (Figs. 2 and 3). This

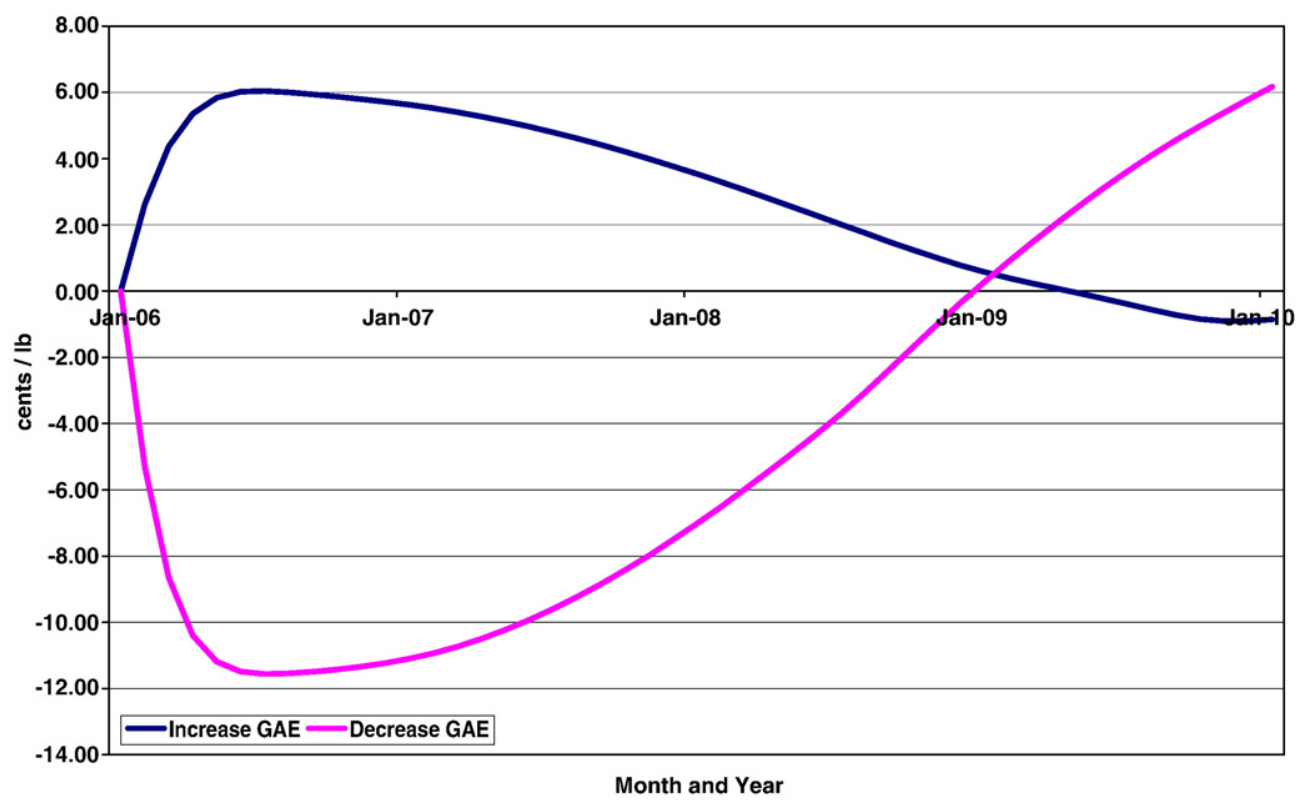

Fig. 7. Cheese prices in response to increases and decreases in generic advertising expenditures, difference from baseline. 


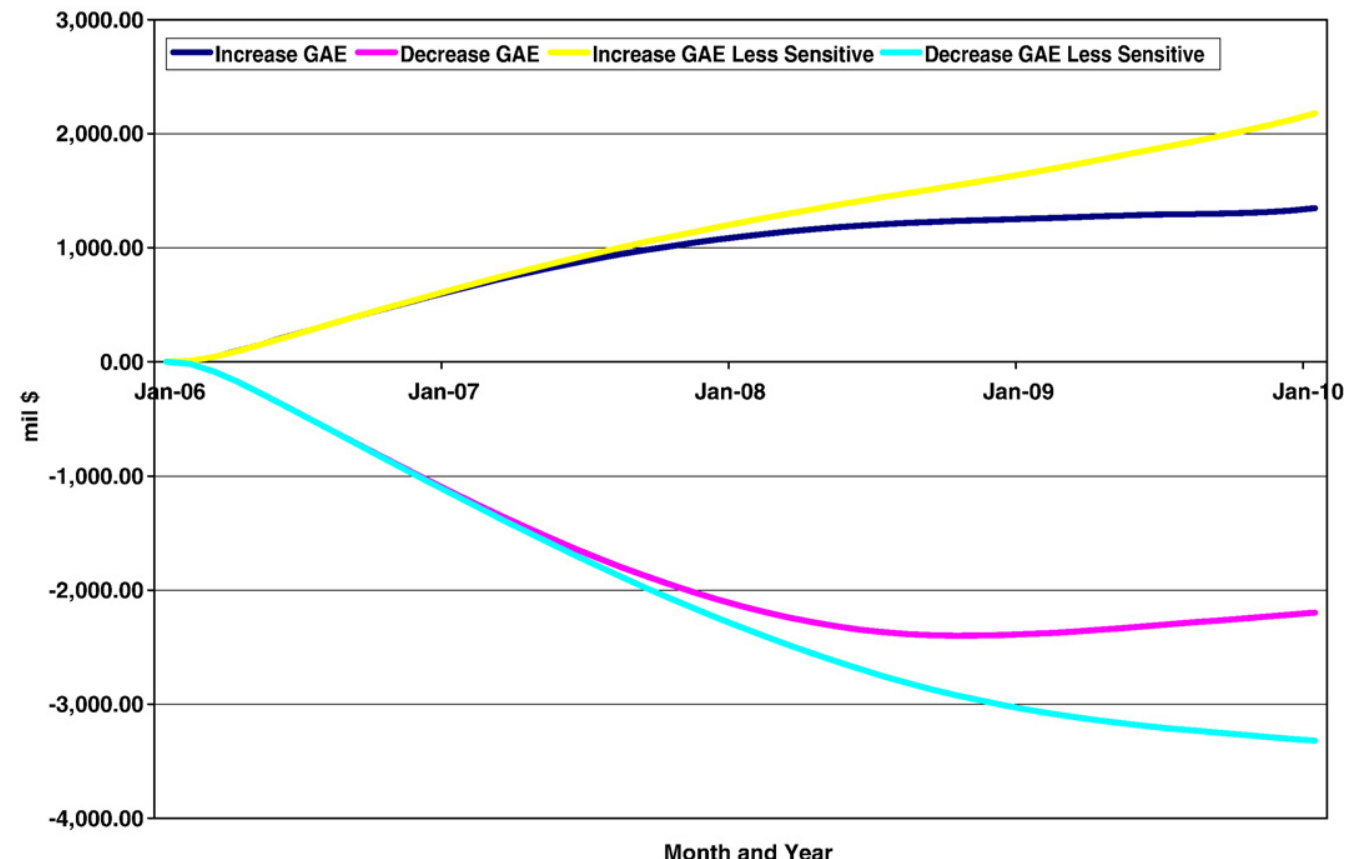

Fig. 8. Cumulative producer revenues in response to increases and decreases in generic advertising expenditures, by sensitivity of capital investment response, difference from baseline.

asymmetric effect arises from the use of the log-linear (constant elasticity) formulation for the effect of advertising expenditures in the advertised product demand equations. An initial rapid decrease in fluid milk and cheese sales is followed by a brief recovery, then continued decline. The initial pattern is essentially the inverse of that observed for price increases, and again results from the interaction of dairy product demand, farm milk prices and milk production. The decrease in demand for fluid milk and cheese reduces the demand for raw milk, which increases the milk available for the manufacture of nonadvertised products, reducing their prices (Fig. 5), the cheese price (Fig. 7) and the minimum regulated price (Fig. 6). The lower milk prices result in lower milk production (Fig. 4) as dairy producers reduce productivity per cow and reduce cow numbers. The combination of a lower milk price and reduced quantity of production reduces cumulative producer revenues (Fig. 8). Over time, consumers respond to lower dairy product prices by increasing demand (Figs. 2 and 3 ) and the reduction in milk production becomes large enough to result in price increases for non-advertised products and cheese (Figs. 5 and 7). This increases the minimum regulated price (Fig. 6) and the rate of decrease for the difference in cumulative producer net revenues slows markedly after January 2008 (Fig. 8).

An important conclusion to be drawn from these results is that milk prices will not always be higher for the scenario with increased generic advertising, nor lower for the scenario with elimination of generic advertising (Fig. 6). As milk production responds over time to initial price increases or decreases through the supply response feedback loop, about 30 months after the increase or decrease, farmer milk prices become higher (for the decrease) or lower (for the increase) than they would have been in the absence of any change in generic advertising expenditures. This effect is also observed in dairy product markets: by 2008 the butter price is lower and by 2009 the cheese price is lower than it would have been in the absence of increased generic advertising. Another important insight is that although the responsiveness of animal average lifetime to relative margins affects the numerical results, the patterns of behavior generally are similar for the more and less responsive scenarios.

One principal objective of generic advertising for fluid milk and cheese is to increase net revenues received by US dairy farmers. The analyses suggest that even when various balancing feedback loops are taken into account, expenditures on generic advertising return far more net revenue to dairy farmers than the expenditures. A permanent doubling of generic advertising expenditures would increase cumulative dairy farmer net revenues by between $\$ 1.3$ and $\$ 2.2$ billion, but would cost only about $\$ 485$ million over the four years from 2006 to 2009 (Fig. 8). Elimination of generic advertising expenditures would reduce dairy farmer net revenues between $\$ 2.2$ and $\$ 3.3$ billion over those 4 years, when the sensitivity of milk production to changes in long-run margin is higher and lower, respectively.

The cumulative net benefit-cost ratio (CNBCR) at time $t$ during the period 2006 to 2009 is:

$$
\mathrm{CNBCR}_{t}=\frac{\int_{t=2006}^{2009} \mathrm{CNR}_{\mathrm{t}}^{\mathrm{S}}-\mathrm{CNR}_{\mathrm{t}}^{\mathrm{B}}}{\int_{t=2006}^{t=2009} \mathrm{CGAE}_{t}^{S}-\mathrm{CGAE}_{t}^{\mathrm{B}}}
$$

where $\mathrm{CNR}_{t}$ represent the cumulative dairy farmer net revenues at time $t$ for scenarios $S$ and the baseline $B$ and $\mathrm{CGAE}_{t}$ are the cumulative generic advertising expenditures for the same scenario. The CNBCR varies over time depending on developments in dairy product markets (Fig. 9). However, for both increases and decreases in generic advertising expenditures the CNBCR grows rapidly then decreases. For a doubling of generic advertising expenditures, the CNBCR initially increases 


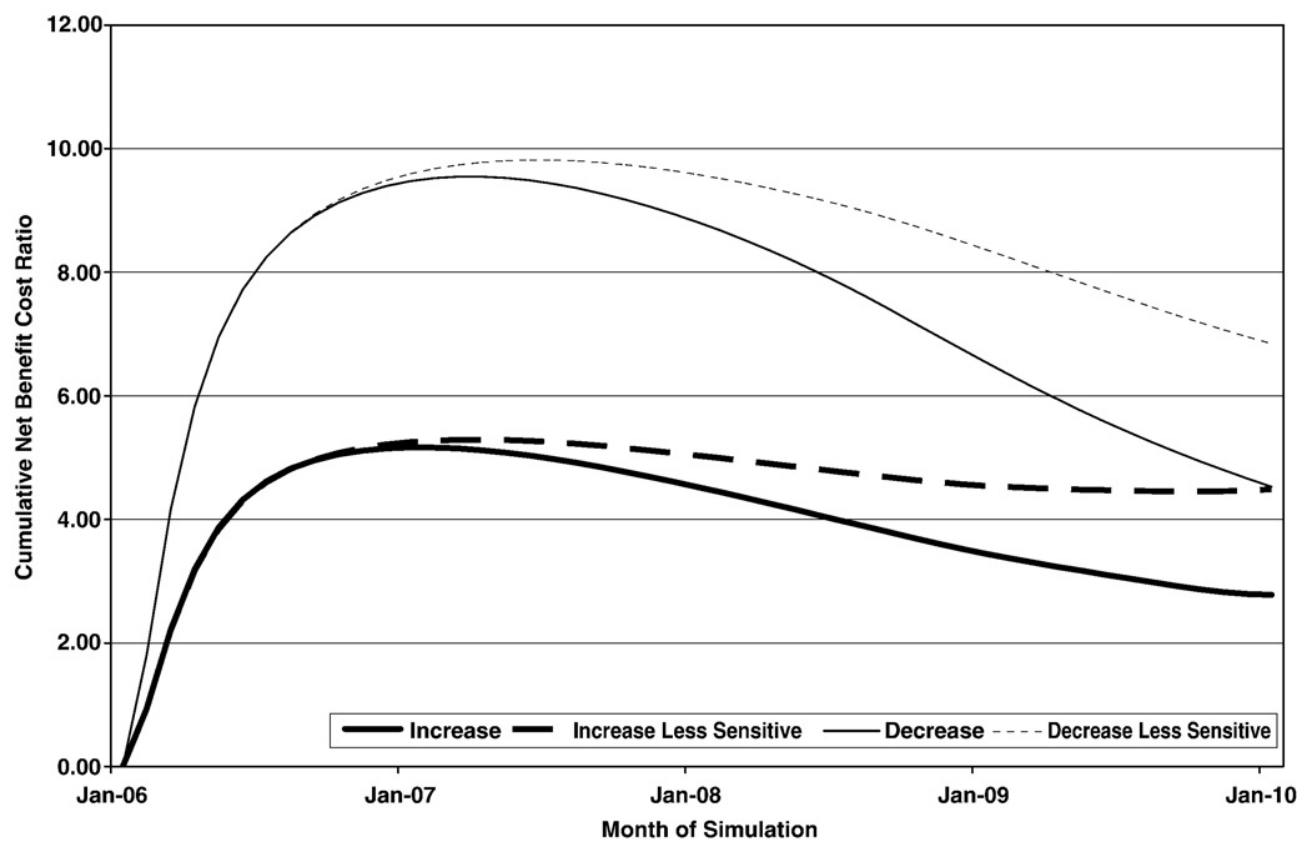

Fig. 9. Dynamic cumulative benefit cost ratio for increases and decreases in generic advertising expenditures, by sensitivity of capital investment response.

to 5.2 and then decreases to 2.8 by the end of simulation. The sensitivity of dairy farmers to average animal lifetime has an impact on the CNBCR for generic advertising expenditure increases, with a value of 4.5 at the end of simulation when supply is less responsive. Both estimates are somewhat lower than past benefit-cost ratios estimated for generic dairy advertising on fluid milk and cheese (e.g., 4.88 for the period 1997 to 2006 by Kaiser, 2007), probably due to better representation of balancing feedback effects. In the absence of generic advertising, the value of the CNBCR is larger (after the initial increase, the value is nearly 10 rather than 5) and ending values range from 4.5 (more sensitive) to 6.8 (less sensitive).

An alternative measure of the returns to generic advertising is the current net benefit cost ratio (CuNBCR), which is the ratio for the CNBCR without the integral signs. Whereas the CNBCR indicates the average return at a given time, the current net benefit cost ratio indicates marginal returns. The CuNBCR increases to about 6.0 for increases in expenditures by mid-2006, then falls below 1.0 in mid-2008. For decreases in expenditures, the initial return increases to nearly 10.0 by mid-2006, but becomes negative in mid-2008. The CuNBCR is sensitive to assumptions about the responsiveness of the average animal lifetime to changes in profitability, with higher values for less sensitive responsiveness.

Overall, the scenarios indicate that on average over the period 2006 to 2009, increased generic advertising expenditures on fluid milk and cheese would increase fluid milk and cheese sales, increase milk production, increase cumulative dairy farmer revenues, and have a CNBCR (but not always the CuNBCR) far larger than 1.0 (Table 2). Conversely, elimination of the generic advertising expenditures would decrease fluid milk and cheese sales, decrease milk production, and decrease cumulative dairy farmer revenues. Moreover, the CNBCR of generic advertising expenditures may be larger at lower expenditure levels, as indicated by the asymmetries in response in doubling and elimination. Thus, the analyses support the effectiveness of generic advertising to enhance dairy farmer well-being, even in the face of multiple feedback loops and product market effects.

\subsection{Allocation of existing expenditures to maximize cumulative dairy farmer revenues}

Although the previous analyses address overall effectiveness of generic advertising expenditures, another relevant question is whether those expenditures have the largest possible effectiveness, that is, that generates the largest cumulative dairy farmer net revenues. Past advertising allocation strategies have tended to emphasize fluid milk because the minimum regulated price paid to farmers is highest for milk used as a beverage. However, because the component content, demand elasticities and predicted growth rates of fluid milk and cheese differ and because they have different impacts on the minimum regulated price formulae, changes in the allocation of generic advertising expenditures could increase dairy farmer net revenues. To explore this hypothesis, simulation runs using the Powell optimization algorithm in Vensim ${ }^{\circledR}$ dynamic simulation software (Ventana Systems, 2005) examine what step change in fluid milk advertising expenditures from funds provided by dairy farmers would maximize cumulative net revenues for dairy farmers. Because fluid milk processors allocate check-off funds only to generic advertising of fluid milk, assumed generic advertising expenditures by fluid milk processors do not change from 2004 levels. Corresponding changes in generic advertising expenditures for cheese and fluid milk by dairy farmers keep overall expenditures on generic advertising expenditures constant. The optimization exercise assumes a permanent, simultaneous step change in allocation of generic advertising expenditures starting in January 2006. (Note that this approach differs from optimization to determine the optimal allocation of advertising expenditures across products 
Table 2

Summary of simulation scenario results

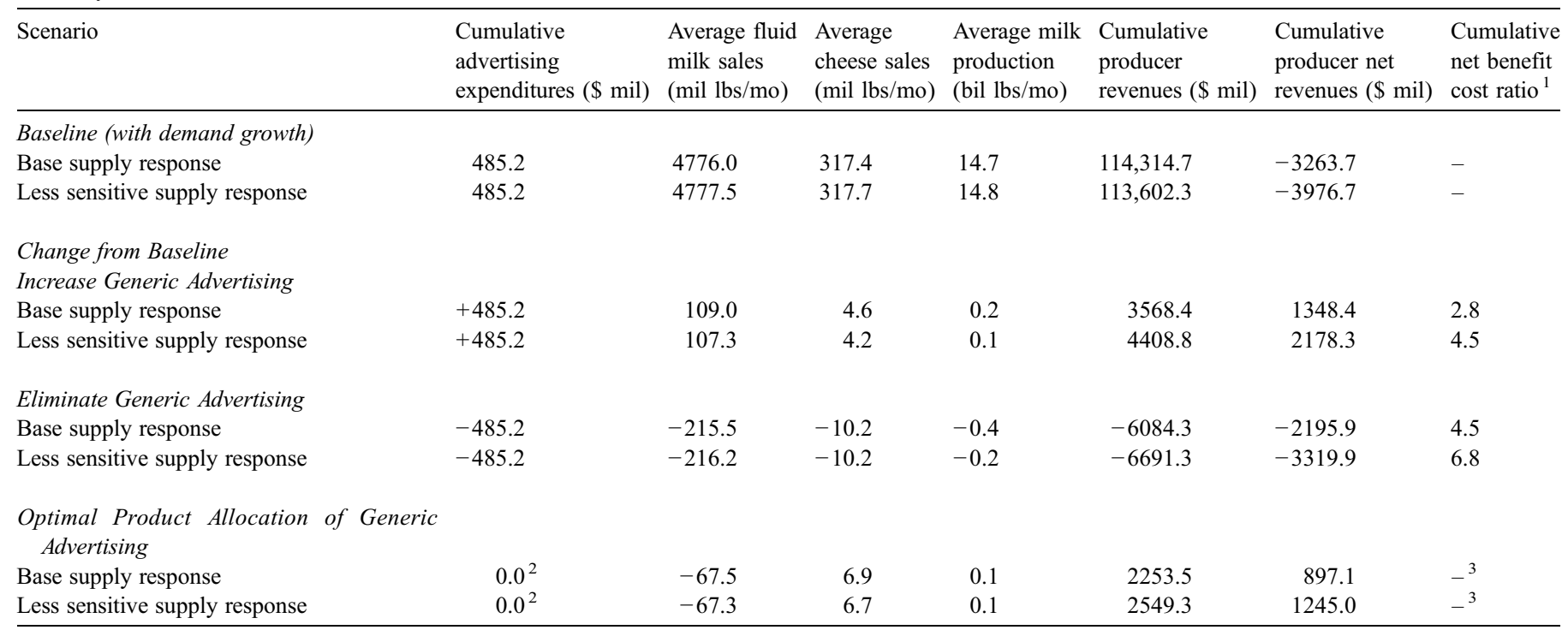

Note: All cumulative values represent the period January 2006 to December 2009.

${ }^{1}$ The cumulative benefit cost ratio is defined as the change in cumulative producer net revenues (from the baseline) divided by the change in cumulative advertising expenditures (from the baseline) at the end of model simulation time. This value is calculated for the reported scenarios, not as a change from the baseline scenario.

${ }^{2}$ No overall change occurs in aggregate generic advertising expenditures. However, $\$ 2.3$ million per month of the funds provided by dairy farmers is switched from fluid milk to cheese advertising expenditures.

${ }^{3}$ Not reported because no change occurs in cumulative advertising expenditures, only a reallocation among the two advertised products.

and over time, which may be addressed with future modifications to the model.)

The optimization results indicate that dairy farmer net revenues could be increased through a complete reallocation of fluid milk advertising expenditures to cheese expenditures for funds provided by dairy farmers (Table 2). A reduction of $100 \%$ in fluid milk advertising expenditures by dairy farmers in expenditures on fluid milk (from about \$2.3 million per month) and an increase of $141 \%$ in cheese expenditures (from $\$ 1.7$ million per month to $\$ 4.1$ million per month) maximizes dairy farmer net revenues. The optimal allocation of advertising expenditures to the two products is not at all sensitive to the responsiveness of average animal lifetime. The optimal reallocation of expenditures results in a reduction in fluid milk sales and an increase in cheese sales, with behaviors similar to those observed for these products in response to a decrease and increase in advertising expenditures, respectively. Producer prices first increase, then decrease, then increase again in response the reallocation, more so in the final months of the simulation than as a part of the initial response. These results indicate that the current level of generic advertising expenditures could, if reallocated away from fluid milk and towards cheese, increase cumulative dairy farmer net revenues by 27 to $31 \%$ compared to the baseline scenarios for the more and less responsive scenarios, respectively. Thus, without increasing expenditures by dairy farmers, reallocation of advertising to cheese would increase net revenues by more than $50 \%$ of the previously-reported increase generated by doubling advertising expenditures (Table 2).

Why does this reallocation increase dairy farmer net revenues, when raw milk sold for beverage use has the highest minimum regulated price? Additional simulation analyses (not reported herein) to control for various factors suggest four principal reasons. First, fluid milk sold to consumers has a fat content less than that of raw milk. To achieve this lower fat content, fluid milk bottlers separate cream from the raw milk. This cream often ends up used to manufacture butter. An increase in fluid milk sales results in additional butter production and lower butter prices, which has an offsetting effect on all of the other minimum pricing formulae. Second, the assumed growth rate of demand for cheese is $1.5 \%$ per year, whereas no growth is assumed for fluid milk consumption. Increases in cheese sales due to generic advertising thus generate increased growth in demand for milk over time.

The minimum price regulation formulae also have a key impact. The minimum regulated price for raw milk used as a beverage depends on the higher of (maximum) of the minimum regulated prices for milk used in cheese or whey or in butter and milk powder. In the 2004 base year, the minimum regulated price for milk used in cheese is higher, and thus also determined the minimum regulated price for fluid milk. An increase in generic advertising expenditures on cheese and a reduction in expenditures on generic fluid milk advertising increases the cheese price (as in Fig. 6), which increases the minimum regulated price for both milk used in cheese and fluid milk. The relative price elasticities of demand for fluid milk and cheese also influence this outcome. An increase in generic advertising expenditures for cheese will increase the price of fluid milk, but fluid milk sales will decrease little because demand is highly inelastic. Conversely, an increase in generic advertising of fluid milk will increase cheese prices, but cheese sales will decrease to a greater extent (ceteris paribus) because cheese demand is more elastic. 


\section{Conclusions and implications}

Although numerous econometric evaluations of generic dairy advertising exist, this study is the first to apply a stockflow-feedback systems model. This approach incorporates the complexities of milk characteristics and economic regulations of the US dairy industry. In particular, the model links milk supply response, dairy economic regulations, and pricing of all milk components to provide a more integrated and comprehensive analysis of generic advertising impacts on the industry.

The analysis reaffirms the findings of other authors that generic dairy advertising is a highly profitable activity on the part of dairy farmers and milk processors. Consideration of multiple balancing feedback loop effects results in estimated cumulative net benefit-cost ratios somewhat lower than previous estimates. Furthermore, unlike previous research, the results include provide detailed time paths of the response of important endogenous variables to changes in generic fluid milk and cheese advertising. One of the more relevant findings is the interaction between changes in demand caused by advertising, milk supply response and prices. Specifically, in the very short run, changes in advertising are positively associated with changes in prices. However, over time, milk production responses significantly erode the price impacts of advertising, as indicated by patterns in both prices and net benefit cost ratios. Thus, the simplistic permanent step in expenditures approach adopted for the scenarios above could be refined to explore optimal inter-temporal allocation of advertising expenditures.

The analysis of the optimal allocation of generic advertising between fluid milk and cheese indicates that dairy farmers could increase their net revenue by transferring all generic fluid milk advertising expenditures into generic cheese advertising assuming fluid milk processors continue generic fluid advertising at 2004 levels. The broader implication is that generic advertising efforts for dairy will be more effective if they increase demand for all dairy components proportional to the composition of raw milk. Nicholson and Stephenson (2006) find similar offsetting effects for promotional efforts focused on milk proteins.

Many potential extensions of the model are possible, but three are the most relevant. One useful extension would be to use the current model to evaluate the optimality of other program activities such as other promotion programs, public relations, sponsorship, and new product research. Funds from dairy farmers support a variety of promotional purposes, including product research and development and other forms of promotion in addition to advertising. Funds from fluid milk processors promote fluid milk only; dairy farmer funds promote dairy products and dairy ingredients. Because money is invested by dairy farmers in promotional activities other than generic advertising, an optimal portfolio analysis would be of tremendous interest to policy makers.

As noted above, the optimal allocation of both advertising expenditures and other promotional activities over time could be analyzed, and has the potential to improve cumulative dairy farmer net revenues through reduction of the effects of the supply response feedback loop (which increases milk supplies). Finally, milk prices and supply response differ on a regional basis. Thus, a more significant extension would be to develop a multi-regional model that explicitly incorporates the regional pricing structure and supply response differences. Such an extension would also allow evaluating optimal advertising spending over geographic markets.

\section{References}

Bishop PM, Nicholson CF. Dairy market impacts of US milk proteins and policy alternatives. Department of Applied Economics and Management, Cornell University; 2004 [Research Bulletin 2004-08].

Bishop PM, Pratt JE, Novakovic AM. Using a joint-input, multi-product formulation to improve spatial price equilibrium models. Department of Agricultural, Resource and Managerial Economics, Cornell University; 1994 [Staff Paper 94-06].

Chung Chanjin, Kaiser Harry M. Distributions of gains from research and promotion in multi-stage productions systems. Am J Agric Econ 1999;81:593-7.

Cornell Program on Dairy Markets and Policy. Dairy contacts listing; 2006 http://www.cpdmp.cornell.edu/CPDMP/Pages/Data/.

Ferrero, Jennifer, Boon, Leen, Kaiser, Harry M, Forker, Olan D. Annotated Bibliography of Generic Commodity Promotion Research (Revised) NICPRE Research Bulletin 96-3, National Institute for Commodity Promotion Research and Evaluation, Department of Agricultural, Resource, and Managerial Economics, Cornell University; 1996.

Kaiser Harry M. "Chapter 3" of USDA Report to Congress on the National Dairy Promotion and Research Program and the National Fluid Milk Processor Promotion Program. Washington, D.C.: USDA; 2006.

Kaiser Harry M. USDA Report to Congress on the National Dairy Promotion and Research Program and the National Fluid Milk Processor Promotion Program. Washington, D.C.: USDA; 2007. Chapter 3.

Kaiser Harry M, Forker Olan D. Analysis of generic dairy advertising scenarios on retail, wholesale, and farm milk markets. A.E. Res. 93-3 Department of Agricultural Economics, Cornell University; 1993.

Kaiser HM, Dong D. Measuring the impacts of fluid milk and dairy marketing. Department of Applied Economics and Management, Cornell University and National Institute for Commodity Promotion and Research Evaluation. [AEM Research Bulletin 2006-05 and NICPRE 2006-02]; 2006.

Liu D, Forker O. Optimal control of generic fluid milk advertising expenditures. Am J Agric Econ 1990;72:1047-55.

Nicholson Charles F, Fiddaman Thomas. Dairy policy and the origins of dairy price volatility. Paper presented at the 21st International Conference of the System Dynamics Society, July 20-24, 2003, New York, NY; 2003.

Nicholson CF, Stephenson MW. Market impacts of high-protein whey product promotion. Report to Dairy Management, Inc., January; 2006.

Pritchett James G, Liu Donald J, Kaiser Harry M. Optimal choice of generic milk advertising expenditures by media type. J Agric Resour Econ 1998;23:155-69.

Schmit TM, Kaiser HM. Decomposing the variation in generic advertising response over time. Am J Agric Econ 2004;86:139-53.

Schmit TM, Kaiser HM. Forecasting fluid milk and cheese demands for the next decade. J Dairy Sci 2006;89:4924-36.

Sterman John D. Business dynamics: systems thinking and modeling for a complex world. Boston: Irwin/McGraw-Hill; 2000.

Vande Kamp Philip R, Kaiser Harry M. Optimal temporal policies in fluid milk advertising. Am J Agric Econ 2000;82:274-86.

Ventana Systems, Inc. Vensim's User's Guide, Version 5; 2005. 